\title{
O URBANO EM RELAÇÃO AO ESPAÇO-TEMPO NO ÂMBITO DAS ADVERSIDADES SOCIAMBIENTAIS
}

\author{
Moacir Apolinário da Costa ${ }^{1}$ \\ Victor Pereira de Sousa ${ }^{2}$
}

Resumo: O espaço geográfico enquanto categoria e objeto de estudo da Geografia, tem o Meio Ambiente como um conceito produzido pelo vínculo da construção e organização da sociedade humana com os elementos naturais, sendo este, princípio para as discussões sobre os problemas socioambientais na atualidade. Este trabalho objetiva ressaltar a correlação inextricável entre o meio ambiente e a sociedade, num panorama onde o urbanismo e a sustentabilidade são destacados como amostras desse elo. Ao lograr dessa temática, pretende-se salientar por meio de pesquisa de gabinete a preocupação, ou falta dela, por parte de políticas locais e globais, no desenvolvimento social e urbano perante o ambiente.

Palavras-chave: Sociedade; Meio Ambiente; Sustentabilidade; Urbanismo; Planejamento.

1 Graduando em Geografia, Universidade do Estado do Mato Grosso (UNEMAT), Brasil. E-mail: moahbtw@gmail.com.

2 Graduando em Geografia, Universidade do Estado do Rio de Janeiro (UERJ), Brasil. E-mail: victordesousa@outlook.com.br. 